\title{
Elektrikli Araçla Periyodik Teknisyen Rotalama ve İstasyon Yeri Seçim Problemi
}

\author{
Mehmet Erdem ${ }^{1 *}$ \\ 1 Ondokuz Mayıs Üniversitesi, Mühendislik Fakültesi, Endüstri Bölümü, Samsun, Türkiye (ORCID: 0000-0003-4396-2149)
}

(International Symposium on Multidisciplinary Studies and Innovative Technologies (ISMSIT) 2020 - 22-24 Ekim 2020)

(DOI: 10.31590/ejosat.818352)

ATIF/REFERENCE: Erdem, M. (2020). Elektrikli Araçla Periyodik Teknisyen Rotalama ve İstasyon Yeri Seçim Problemi. Avrupa Bilim ve Teknoloji Dergisi, (Özel Sayı), 16-27.

\section{$\ddot{O} \mathbf{z}$}

Bu çalışmada Elektrikli Araçla Periyodik Teknisyen Rotalama ve Şarj İstasyonu Yeri Belirleme Problemi tanımlanmıştır. Problemde farklı coğrafi bölgelerde bulunan müşterilere bir dizi önleyici ve düzeltici bakım ve yedek parça tedariki hizmetleri sunulmaktadır. Ayrıca müşteriler, planlama ufku boyunca farklı zaman dilimlerinde bu ve benzeri hizmetleri talep edebilmektedir. Farklı yetkinliklere sahip olan teknisyenlerden takımlar oluşturulup müşterilerin bulunduğu ortamda talep edilen hizmetler sağlanmaktadır. Hali hazırda iş gücü çizelgeleme ve rotalama probleminin NP-zor sınıfta yer aldığı göz önüne alınırsa, tanımlanan problemde aynı sınıfta yer almaktadır. Literatürden farklı olarak bu çalışmada, teknisyenlerin müşterilere ulaşmada klasik içten yanmalı motorlu araçlar kullanması yerine elektrikli araçlarla müşterilere ulaşması göz önüne alınmıştır. Bu sayede fosil yakıt kullanımı azaltılarak, bu yakıtların ulaşım kaynaklı çevresel etkilerinin azaltılması gerçekleşebilecektir. Ayrıca, çevre dostu elektrikli araçların işletme maliyetlerinin klasik içten yanmalı motorlu araçlara göre daha az olması da işletmelerin karşısına ekonomik bir alternatif olarak ortaya çıkmaktadır. Elektrikli araçların avantajlarının yanı sıra kısıtlı menzili onları istasyon kullanmaya bağımlı kılmaktadır. Bu sebepten ötürü bu araçların fosil yakıt kullanan araçlarla rekabet edebilmesi için rotalama planlarının da etkin bir şekilde yapılması gerekmektedir. Tanımlanan problemde planlama ufku boyunca takımlar için günlük çizelge ve rota oluşturmanın yanı sıra, elektrikli araçların şarj durumunun takibi ve istasyon yeri belirleme kararı da bulunmaktadır. Ayrıca teknisyenlerin yasal dinlenme süreleri de göz önüne alınmıştır. Belirli çalışma süresini tamamlayan teknisyenlerin mola vererek dinlenmesi sağlanmıştır. Önerilen karma tam sayılı programlama ile problem modellenmiştir. Gerçek hayat verisinden üretilen veri seti kesin yöntemle çözülmüştür. Ayrıca üretilen farklı boyutlardaki problemlerin çözümü için değişken komşu arama sezgiseli kullanılmıştır. Elde edilen kesin sonuçlar değişken komşu arama sezgiseli ile karşılaştırılmıştır. Gerçekleştirilen hesaplamalı karşılaştırma analizleri sezgisel yöntemin optimum çözümü bulabildiğini ve CPLEX çözücüsünden daha iyi sonuçlar ürettiğini ortaya koymaktadır.

\section{Electric Multiperiod Technician Routing and Charging Station Location Problem}

\begin{abstract}
In this study, Electric Multiperiodic Technician Routing and Charging Station Location Problem is defined. A series of preventive and corrective maintenance-repair and spare parts supply services are offered to customers located in different geographical regions of the problem. In addition, the customers can request these tasks in different time windows throughout the planning horizon. Teams of technicians with different competencies are formed and allocated to these tasks that are provided in the customer locations. Considering that the workforce scheduling and routing problem is in the NP-hard class, thus the defined problem is also in the same class. Unlike the literature, in this study, it is taken into account that technicians reach customers with electric vehicles instead of using conventional internal combustion engine vehicles. In this way, it will be possible to reduce the use of fossil fuels and the environmental impact of
\end{abstract}

\footnotetext{
* Sorumlu Yazar: Ondokuz Üniversitesi, Mühendislik Fakültesi, Endüstri Bölümü, Samsun, Türkiye, ORCID: 0000-0003-4396-2149,

mehmet.erdem@omu.edu.tr
} 
these fuels due to transportation. In addition, due to the operating costs of electric vehicles are lower than those of conventional vehicles, electric vehicles emerge as an economical option for businesses. In addition to their advantages, the limited range of electric vehicles makes them dependent on using charging stations. For this reason, routing plans need to be made efficiently in order for these vehicles to compete with conventional vehicles. In the proposed problem, while creating a daily schedule and route for the teams throughout the planning horizon, tracking the state of charge of the vehicles and determining the location of the charging station are also considered. In addition, the legal rest periods of the technicians are also taken into account. The problem is modelled with the mixed integer programming formulation. Furthermore, the data set generated from the real-life instances. In order to solve the problem variable neighbourhood search heuristic is used. Computational comparisons are conducted to compare the performance of the heuristic. The results indicate that it can find the optimum solutions. Moreover, the heuristic is able to produces better results than the CPLEX solver in a reasonable time.

Keywords: Electric Vehicles, Technician Routing, Charging Station Location Problem, Variable Neighbourhood Search.

\section{Giriş}

Personel çizelgeleme problemi, bir işletmenin mal veya hizmetlerine yönelik müşterilerden gelen talebi karşılayabilmesi için istihdam ettiği personeli için zaman çizelgeleri oluşturma süreci olarak tanımlanmaktadır (Ernst, Jiang, Krishnamoorthy, ve Sier, 2004). Ele alınan çalışmada, servis hizmeti sağlayan işletme farklı coğrafi bölgelerde mukim müşterilere bir dizi önleyici, düzeltici bakım, arıza teşhis hizmeti ile makine yedek parçası teslimatını yapmaktadır. Bahsi geçen bu hizmetler, müşterilerin adresinde verildiğinden dolayı bir dizi teknisyen ekibinin ziyaretini gerektirirler. Müşterilerin farklı zaman dilimlerindeki farklı deneyim ve tecrübe gerektiren hizmetlerine cevap vermek problemin bir boyutu iken ve işletmenin bunu minimum maliyetle ve yeterli seviyede kalifiye personelle yapmak istemesi ise problemin diğer boyutudur. Farklı perspektifler içeren problem karmaşık bir yapıya sahiptir ve bu sebeplerden ötürü iyi bir sonuç bulmak zordur.

Ulaşım sektörünün negatif etkileri üzerine farkındalık gittikçe artmaktadır ve gelişmiş birçok ülke yakın gelecekte elektrikli araç kullanımıyla ilgili araştırma yapmaktadır (European-Commission, 2014; European Environment Agency, 2014). Ayrıca yakın gelecekte ulaşımdan kaynaklı sera gazı etkilerini azaltmak için ülkeler hedefler koymaktadırlar (European-Commission, 2011; European Comission 2014). Elektrikli araçlar bu ve benzeri negatif etkilerin azaltılması için bir firsattır. Ayrıca, bu araçların bakım maliyetlerinin klasik içten yanmalı motorlu araçlara göre daha ekonomiktir. Birçok pilot projede elektrikli filo kullanımı hali hazırda UPS ve DHL gibi lojistik firmalarında devam etmektedir (Schiffer ve Walther, 2017). Elektrikli araçların olumlu yönlerinin yanında, kısa menzili, uzun şarj süreleri, şarj istasyonlarının eksikliği bu araçların kullanımında göz önüne alınması gereken kararlardandır.

Literatürden farklı olarak bu çalışmada, teknisyenlerin müşterilere ulaşmada klasik içten yanmalı motorlu araçlar kullanması yerine elektrikli araçlarla müşterilere ulaşması göz önüne alınmıştır. Ayrıca problemde şarj istasyonunun açılıp açılmaması kararı da dikkate alınmıştır. Klasik personel rotalama ve çizelgeleme problemine, elektrikli araçlar ve onların kullandığı istasyonlar dâhil edilerek literatürde ilk kez Elektrikli Araçla Periyodik Teknisyen Rotalama ve İstasyon Yeri Seçim Problemi tanımlanmıştır.

Elektrikli araç rotalama problemleri bakımından Schiffer ve Walther (2017) rotalama, çizelgeleme, şarj ve istasyon kararlarını ele alsalar da bu çalışmada teknisyenlerin özellikleri ve dinlenme süreleri dikkate alınmamıştır. Mevcut teknisyen rotalama ve çizelgeleme problemlerinin hiçbiri önerilen problemdeki eş zamanlı rotalama, çizelgeleme, şarj durumunu takip etme ve şarj istasyonu konumlandırma kararlarını içermemektedir. Mevcut problemler Tablo 1'de özetlenmiştir. Dördüncü sütunda modellere ilişkin amaç, beşinci sütunda ise kısıtlar yer almaktadır.

$\mathrm{Bu}$ çalışma şu şekilde yapılandırılmıştır: Bölüm 2'de Elektrikli Araçla Periyodik Teknisyen Rotalama ve İstasyon Yeri Seçim Problemi tanıtılmış ve ayrıntılı olarak açıklanmıştır. Bölüm 3’te, sezgisel çözüm yöntemi sunulmuştur. Farklı amaç işlevlerine ilişkin önerilen modellerin sezgisel ve tam sayılı model sonuçları Bölüm 4'te sunulmuştur. Çalışmaya ilişkin sonuç ise Bölüm 5 'te sunulmuştur. 
Tablo 1. Önceki çalışmalarda dikkate alınan özelliklere genel bakış

\begin{tabular}{|c|c|c|c|c|c|c|c|c|c|}
\hline \multirow[b]{2}{*}{ Yazarlar } & \multirow{2}{*}{$\begin{array}{l}\text { Planlama } \\
\text { ufku }\end{array}$} & \multirow{2}{*}{$\begin{array}{l}\text { Matematiksel } \\
\text { model }\end{array}$} & \multirow[b]{2}{*}{ Amaç } & \multicolumn{5}{|l|}{ Kisitlar } & \multirow{2}{*}{$\begin{array}{l}\text { Çözüm } \\
\text { yöntemi }\end{array}$} \\
\hline & & & & $\begin{array}{l}\text { Zaman } \\
\text { penceresi }\end{array}$ & $\begin{array}{l}\text { Takım } \\
\text { oluşturma }\end{array}$ & $\begin{array}{l}\text { Dinlenme } \\
\text { süreleri }\end{array}$ & $\begin{array}{l}\text { Yeterlilik / } \\
\text { beceri }\end{array}$ & $\begin{array}{l}\text { Enerji } \\
\text { kısitları }\end{array}$ & \\
\hline $\begin{array}{l}\text { Cordeau, Laporte, } \\
\text { Pasin, ve Ropke } \\
(2010)\end{array}$ & Tek dönem & + & $\begin{array}{l}\text { İşlerin ağırlıklı } \\
\text { tamamlanma } \\
\text { zamanı }\end{array}$ & + & + & - & + & - & $\begin{array}{l}\text { Uyarlanabilir } \\
\text { büyük komşu } \\
\text { arama }\end{array}$ \\
\hline $\begin{array}{l}\text { Kovacs, Parragh, } \\
\text { Doerner, ve Hartl } \\
(2012)\end{array}$ & Tek dönem & + & $\begin{array}{l}\text { Seyahat } \\
\text { maliyeti }\end{array}$ & + & + & - & + & - & $\begin{array}{l}\text { Uyarlanabilir } \\
\text { büyük komşu } \\
\text { arama }\end{array}$ \\
\hline $\begin{array}{l}\text { Dohn, Kolind, ve } \\
\text { Clausen (2009) }\end{array}$ & Tek dönem & + & $\begin{array}{l}\text { Atanan iş } \\
\text { sayısı }\end{array}$ & + & - & & - & - & $\begin{array}{l}\text { Dal-Ücret } \\
\text { Algoritması }\end{array}$ \\
\hline Xu ve Chiu (2001) & Tek dönem & + & $\begin{array}{l}\text { Atanan } \\
\text { teknisyen } \\
\text { say1s1 }\end{array}$ & - & - & - & - & - & $\begin{array}{l}\text { Yerel arama, } \\
\text { açgözlü } \\
\text { rastgele } \\
\text { uyarlamalı } \\
\text { arama }\end{array}$ \\
\hline $\begin{array}{l}\text { Castillo-Salazar, } \\
\text { Landa-Silva, ve } \\
\text { Qu (2014) }\end{array}$ & Tek dönem & + & $\begin{array}{l}\text { Mesafe ve } \\
\text { teknisyen } \\
\text { maliyeti }\end{array}$ & + & - & - & + & - & $\begin{array}{l}\text { Kesin çözüm } \\
\text { yöntemi }\end{array}$ \\
\hline $\begin{array}{l}\text { Schiffer ve } \\
\text { Walther (2017) }\end{array}$ & Tek dönem & + & $\begin{array}{c}\text { Mesafe, araç } \\
\text { ve istasyon } \\
\text { kullanımı }\end{array}$ & + & - & - & - & + & $\begin{array}{l}\text { Kesin çözüm } \\
\text { yöntemi }\end{array}$ \\
\hline $\begin{array}{l}\text { Zamorano ve } \\
\text { Stolletz (2017) }\end{array}$ & $\begin{array}{l}\text { Çok } \\
\text { dönem }\end{array}$ & + & $\begin{array}{l}\text { Seyahat, } \\
\text { bekleme ve } \\
\text { fazla mesai } \\
\text { maliyeti }\end{array}$ & + & + & - & + & - & $\begin{array}{l}\text { Dal-Ücret } \\
\text { Algoritması }\end{array}$ \\
\hline Yapılan Çalışma & $\begin{array}{l}\text { Çok } \\
\text { dönem }\end{array}$ & + & $\begin{array}{c}\text { Seyahat, } \\
\text { enerji, araç } \\
\text { ve istasyon } \\
\text { kullanım } \\
\text { maliyeti }\end{array}$ & + & + & + & + & + & $\begin{array}{l}\text { Değişken } \\
\text { komşu arama }\end{array}$ \\
\hline
\end{tabular}




\section{Problem Tanımı}

Elektrikli araçla periyodik teknisyen rotalama ve istasyon yeri seçim problemi birkaç farklı kararı içermektedir. Esasen, ana karar planlama ufku boyunca her müşteri talebinin, oluşturulan takıma atanmasıdır. Atamada işlerin ve teknisyenlerin yeterlilik seviyesinin göz önüne alınması gerekmektedir. Başka bir deyişle teknisyenlerden oluşturulan takımların işi yapabilecek eşit veya daha yüksek bir seviyeye sahip olması gerekmektedir. Ayrıca, müşterilerin istedikleri ziyaret zaman aralıkları ve çalışanların çalışma süreleri de dikkate alınmalidir.

Bununla birlikte yapılan çalışmada çalışan teknisyenler için mola süreleri de dikkate alınarak çizelgeler oluşturulmuştur. Açıklamak gerekirse teknisyenler gün içinden $\beta$ süresinden fazla çalışırlarsa $p^{\prime}$ mola süresi kadar dinlenmek zorundadır. Bu mola müşterinin bulunduğu lokasyonda hizmetin öncesinde veya sonrasında olabileceği gibi, teknisyen şarj istasyonunda da mola alabilmektedir.

Araçların rota başlangıç ve bitiş düğümü sırasıyla $\{0\}$ ve $\{n\}$ ile gösterilmiş olup tam şarjla depodan ayrılmaktadır. Gerekli olduğunda araçlar şarj istasyonuna uğrayarak yeteri kadar enerji depolamaktadır. Yani kısmi şarja izin verilmektedir. Araçların enerji tüketimi mesafenin lineer bir fonksiyonudur. Aracın mesafe başına enerji tüketimi ve birim zamanda şarj süresi sırasıyla $r$ ve $u$ ile gösterilmiştir.

Müşterilerin talep ettiği bakım ve onarım işleri görev olarak tanımlanmış olup, müşteriler haftada bir veya birden fazla kez planlama ufkunda önceden belirlenmiş günlerde ziyaret edilebilmektedir. Müşteri ziyaretleri günün farklı zaman diliminde ve farklı sürelerde olabilmektedir, başka bir deyişle sabit değildir. Örneğin, düzeltici bakım hizmeti Salı günü saat 09:30-14:00 arasında veya parça teslimatı Perşembe günü saat 09:00 ile 12:00 arasında yapılabilir. Bu ziyaretlerin zaman penceresi $\left[a_{i d}, b_{i d}\right]$ ve süresi ise $p_{i d}$ ile ifade edilmekte olup, mesai saati ise $[a, b]$ ile tanımlanmıştır.

Teknisyenlerden takımlar oluşturulmakta ve yukarıda bahsi geçen işlere atanmaktadır. Takımda bulunması gereken teknisyen sayısı $\Theta$ ile tanımlanmaktadır. Teknisyenlerin ve görevlerin farklı yetkinlikleri ve yeterlilik seviyeleri $Q$ ve $L$ ile tanımlanmıştır. Oluşturulan takımların işlere atanırken, teknisyenlerin yeterlilik seviyesinin toplamı görevin seviyesinden eşit veya daha yüksek olması gerekmektedir. Aksi durumda atama yapılmayacaktır.

İkili karar değişkeni $x_{i j k d} i$. düğümden $j$. düğüme $k$ takımının $d$. günde gidip gitmediğini göstermektedir. Atamaya ilişkin ikili karar değişkenlerinden bahsetmek gerekirse: $y_{i k d}$, i. işe k takımının $d$. günde atanıp atanmadığını ve $z_{m k} m$ teknisyeninin $k$ takımına $d$. günde atanıp atanmadığını ifade etmektedir. Mola için $\delta_{k d}$ tanımlanmış olup $k$ takımının $d$. günde mola verip vermemesini kontrol etmektedir. Ayrıca, $w_{i d} i$. istasyonun $d$. günde açılıp açılmadığını göstermektedir. Problemde zaman karar değişkeni $s_{i k d}$ ile tanımlanmış olup $i$. düğüme veya $P$ molasına $k$ takımının $d$. günde başlama zamanını ifade etmektedir. Son olarak şarj kararlarını üç farklı değişken ile takip edilmektedir. $o_{i k d} i$ düğümündeki $k$ takımının $d$. günde enerji seviyesini, $h_{i k d} i$. şarj istasyonundan ayrılırken ki $k$ takımının/ aracının $d$. günde enerji seviyesini ve $g_{i k d} k$ takımının $i$. şarj istasyonundaki $d$. günde şarj süresini tutmaktadır. Modellerde kullanılan gösterim Tablo 2'de özetlenmiştir. Bir sonraki kısımda modelin amaçlarından ve kısıtlardan teker teker bahsedilecek. 
Tablo 2. Gösterim

\begin{tabular}{|c|c|}
\hline \multicolumn{2}{|l|}{ Kümeler } \\
\hline$D$ & Gün kümesi \\
\hline$I$ & Görev kümesi \\
\hline$K$ & Takım \\
\hline M & Teknisyen \\
\hline$L$ & Yeterlilik seviyesi \\
\hline$Q$ & Yetkinlik \\
\hline S & Şarj istasyonu \\
\hline$S^{\prime}$ & Kopya şarj istasyonu \\
\hline$B$ & Mola düğümü \\
\hline$N=I \cup S^{\prime}$ & $\begin{array}{l}\text { Görev ve kopya şarj istasyonlarını gösterir düğ̈̈m } \\
\text { kümesi }\end{array}$ \\
\hline$N_{0}=N \cup\{0\}, N_{n}=N \cup\{n\}$ & Başlangıç ve bitiş düğümlerini içeren düğüm kümesi \\
\hline \multicolumn{2}{|l|}{ Parametreler } \\
\hline$c_{i j}$ & $i$ ve $j$ düğümleri arası mesafe \\
\hline$[a, b]$ & Mesai başlangıç ve bitiş saatleri \\
\hline$\left[a_{i d}, b_{i d}\right]$ & $i$ işinin $d$. günde başlangıç ve bitiş saati \\
\hline$p_{i d}$ & $i$ işinin $d$. günde yapılma süresi \\
\hline$p^{\prime}$ & Mola süresi \\
\hline$\pi$ & Aracın hızı \\
\hline$\zeta_{m q l}$ & $\begin{array}{l}m \text { teknisyeni } q \text { yeterliliğine } l \text { seviyesinde sahip ise } 1 \text {, } \\
\text { diğer durumda } 0\end{array}$ \\
\hline$v_{i q l}$ & $\begin{array}{l}i \text { işi q yeterliliğine } 1 \text { seviyesinde gereksinim duyuyorsa } \\
1 \text {, diğer durumda } 0\end{array}$ \\
\hline$f_{i d}$ & $i$ işi $d$. günde isteniyorsa 1 , diğer durumda 0 \\
\hline$\theta$ & Takımda bulunması gereken teknisyen sayısı \\
\hline$r$ & Mesafe başına enerji tüketimi \\
\hline$u$ & Birim zamanda şarj süresi \\
\hline$\alpha$ & Mesai süresi (mola dahil) \\
\hline$\beta$ & Molasız çalıșlabilen mesai süresi \\
\hline$p$ & Mola süresi \\
\hline \multicolumn{2}{|l|}{ Karar Değişkenleri } \\
\hline$x_{i j k d}$ & $\begin{array}{l}\text { i. düğümden } j \text {. düğüme } k \text { takım1 } d \text {. günde giderse } 1 \text {, } \\
\text { diğer durumda } 0\end{array}$ \\
\hline$y_{i k d}$ & $i$. işe $k$ takımı $d$. günde atandıysa 1 , diğer durumda 0 \\
\hline$z_{m k d}$ & $\begin{array}{l}m \text { teknisyeni } k \text { takımına } d \text {. günde atandıysa } 1 \text {, diğer } \\
\text { durumda } 0\end{array}$ \\
\hline$\delta_{k d}$ & $k$ takımı $d$. günde mola verdiyse 1 , diğer durumda 0 \\
\hline$w_{i d}$ & $i$. istasyon d. günde kullanıldıysa/açıldıysa \\
\hline$s_{i k d}$ & $\begin{array}{l}\text { i. dügüume veya } P \text { molasına } k \text { takımının } d \text {. günde } \\
\text { başlama zamanı }\end{array}$ \\
\hline$o_{i k d}$ & $\begin{array}{l}i \text { düğümündeki } k \text { takımının/aracının } d \text {. günde enerji } \\
\text { seviyesi }\end{array}$ \\
\hline$h_{i k d}$ & $\begin{array}{l}\text { i. şarj istasyonundan ayrılırken ki } k \text { takımının/ aracının } \\
\text { d. günde enerji seviyesi }\end{array}$ \\
\hline$g_{i k d}$ & $k$ takımının $i$. şarj istasyonundaki $d$. günde şarj süresi \\
\hline
\end{tabular}

Ele alınan problem planlama görevini farklı planlama perspektiflerinden ele almak için kullanılabilir. Böylelikle, temeldeki ana fikre bağlı olarak farklı amaç fonksiyonları kullanılabilir. İki farklı fonksiyon kullanılmış olup sırasıyla bahsedilecektir. Amaç (1) minimizasyonuyla, toplam kat edilen mesafe, kullanılan elektrikli araç sayısı ve bu araçların şarj maliyeti planlama ufku boyunca dikkate alınmaktadır. Amaç (2) ise (1)'den farklı olarak kullanılan/açılan şarj istasyonu sayısını da dikkate almaktadır.

$$
\begin{aligned}
& \text { Min } \sum_{k \in K} \sum_{i \in N_{0}} \sum_{j \in N_{n}} \sum_{d \in D} c_{i j} x_{i k k d}+\sum_{j \in N} \sum_{k \in T} \sum_{d \in D} x_{0 j k d}+\sum_{i \in F^{\prime}} \sum_{k \in T} \sum_{d \in D} g_{i k d} \\
& \text { Min } \sum_{k \in K} \sum_{i \in N_{0}} \sum_{j \in N_{n}} \sum_{d \in D} c_{i j} x_{i j k d}+\sum_{j \in N} \sum_{k \in T} \sum_{d \in D} x_{0 j k d}+\sum_{i \in F^{\prime}} \sum_{k \in T} \sum_{d \in D} g_{i k d}+\sum_{i \in F} \sum_{d \in D} w_{i d}
\end{aligned}
$$

$\mathrm{Bu}$ kısımda ise sirasıly kullanılan kısitlardan bahsedilecektir. 


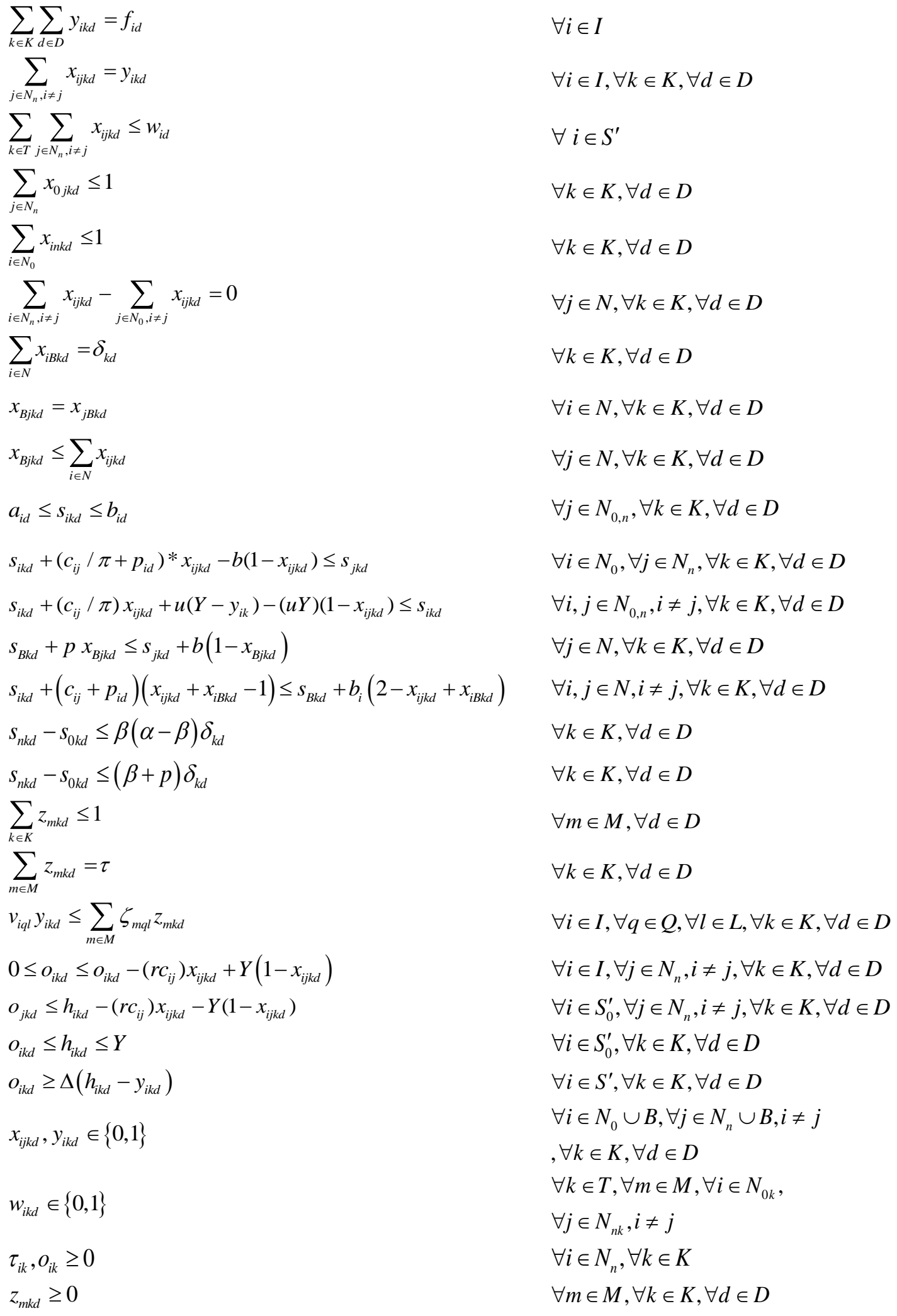

Kısıt (3) işlerin takımlara talep edilen günde atanmasını sağlarken, kısıt (4) atama karar değişkeni ile rotalama karar değişkeni arasındaki bağlantıyı sağlar. Kısıt (5) ise takımların şarj istasyonlarına gerekmedikçe uğramasını engeller. Ayrıca bu kısıt ile herhangi bir şarj istasyonuna bir araç uğrarsa istasyon açılmış olur ve amaç fonksiyonunda açılma maliyeti maliyete eklenir. Kısıt (6) ve (7) takımların rotalarının depoda başlayıp bitmesini sağlamaktadır. Akışın korunumu kısıt (8) ile göz önüne alınmışıtır. Eğer takım molaya gerek duyarsa, gereken karar değişkeni kısıt (9)'da tanımlanmıştır. Molalar, müşterinin veya istasyonun bulunduğu bölgede yapılması varsayılmıştır. Uygun başlangıç zamanı elde edebilmek için, kısıt (10)'da molanın öncesi ve sonrası aynı düğüm göz önüne alınmıştır. Kısıt (11) takımların ziyaret ettikleri lokasyonda mola almalarını sağlamaktadır. Modelin zaman kısıtları (12)-(16) arasında ifade edilmiştir. Kısıt (12) teknisyenlerin işi tanımlanan zaman penceresi içerisinde yapmasını ve mesai saatlerinde çalışmasını sağlamaktadır. Kısıt (13) bir sonraki işin başlama zamanını sjkd, önceki işin başlama zamanı $s_{i k d}$ hizmet süresi $p_{i d}$ ve seyahat süresini $c_{i j} / \pi$ dikkate alarak hesaplamaktadır. Kısıt (14) ise önceki kısıttan farklı olarak şarj istasyonunda aracın şarj süresini dikkate almaktadır. Kısıt (15)-(16) ise e-ISSN: 2148-2683 
molanın zamanını gözetmektedir. Takımların çalışma saatleri kısıt (17)-(18) ile sınırlandııılmıştır. Takımlar mola verdiğinde, çalışma saatinin $\beta$ 'dan büyük veya eşit olması gerekirken $\alpha$ 'dan ise küçük veya eşit olması gerekmektedir. Molasız çalışma durumunda ise çalışma zamanının $\beta$ 'dan küçük olması beklenmektedir. Kısıt (19) planlama boyunca bir gün içeresinde bir teknisyenin en fazla bir takıma atanmasını sağlamaktadır. Kısıt (20) takımda yer alması gerekli personel sayısını sağlamaktadır. Kısıt (21) iş ve teknisyen yeterlilik seviyesini gözeterek uygun teknisyenlerin seçimine göre takımlara atama yapmamızı sağlamaktadır. Şarj kısıtları (22)-(24) ile ifade edilmiştir. Aracın seyahat ettiği mesafe boyunca harcadığı enerji kısıt (22) ile takip edilmektedir. Şarj istasyonundan ayrıldığındaki enerji seviyesi ise kısıt (23) ile hesaplanmaktadır. Araç şarj istasyonundan ayrıldığında şarj seviyesi için alt ve üst limiti kısıt (24) ile belirlenmiştir. Kısmi şarj yüklemesi ise kısıt (25) ile hesaplanmaktadır. Karar değişkenlerine ilişkin tanımlamalar ise kısıt (26)-(29) arasında verilmiştir.

Dolayısıyla Model 1 amaç (1) ve kısıtlar (3)-(4), (6)-(29), Model 2 ise amaç (2) ve kısıtlar (3)-(29) tarafindan oluşturulmaktadır.

\section{Değişken komşu arama sezgiseli}

$\mathrm{Bu}$ çalışmada, elektrikli araçla periyodik teknisyen rotalama ve istasyon yeri seçim problemi için değişken komşu arama (DKA) sezgiseli kullanılmıştır. DKA, kombinatoryal optimazasyon problemlerini çözmek için ortaya atılmıştır. Prensibi komşuluk yapısını sistematik bir şekilde değiştirerek hem yerel en iyiyi bulması hem de yerel tuzaklardan takılmadan çıkması esasına dayanır (Hansen, Mladenović, Brimberg, ve Pérez, 2010). Birinci aşamada teknisyenlerden takımlar oluşturulur ve talep edilen görevler uygun bir şekilde ilk önce güne daha sonra zaman penceresine göre sıralanır ve teknisyenlerden takımlar oluşturulan takımlara atanır. Böylelikle başlangıç çözümü elde edilir. Çalkalama için yer değiştirme operatörü kullanılır. Yerel aramada takıldığı durumda bu operatör devreye girer. Yerel arama için yer değiştirme, ekleme operatörleri kullanılmaktadır. Ayrıca istasyon ekleme ve gereksiz istasyonları çözümden elemek için de iki farklı operatör de gerektiği durumlarda kullanılmaktadır. Yine molalar için mola ekleme operatörü de kullanılarak çözümün tüm kısıtları sağladığı yani fizibilitenin korunduğu garanti edilir. Tanımlanan komşuluk yapısı içinde, yeni çözüm kabul edilirse, komşuluk yapısı en başa döner, aksi durumda bir sonraki komşuluk kullanılır. En iyi çözümden daha iyi bir çözüme ulaşıldığında, en iyi çözüm güncellenir. En sonunda durdurma kriteri sağlanana kadar algoritma çalışır.

\section{Araştırma Sonuçları ve Tartışma}

Bu çalışmada kullanılan veri, bakım hizmeti sağlayıcısından alınan gerçek hayat probleminden türetilmiştir Zamorano ve Stolletz (2017). Mesai süresi, müşteri zaman penceresi bu veriden benzer dağılım gözetilerek üretilmiştir. İlgili makalede mesafeye ilişkin veri beyan edilmediğinden, benzer şekilde bizde Google Haritalardan (Google, 2020) Samsun ili ve ilçeleri gözetilerek farklı konumlardaki hesaplanmıştır. Şarj istasyonları için konumlandırma mevcut akaryakıt istasyonları içerisinde varsayılmıştır. Araçların tam şarjla kat ettiği mesafe $165 \mathrm{~km}$ ve tam şarj süresi $180 \mathrm{dk}$ olarak göz önüne alınmıştır (Edelstein, 2017; Schmidt, 2017). Amaç fonksiyonu için hesaplanan maliyet kalemleri ise sırasıyla birim $(\mathrm{km})$ başına maliyet $\$ 0.06$, kullanılan araç başına maliyet $\$ 60$, birim zamanda şarj olma maliyeti $\$ 0,03$ ve istasyon kullanım maliyeti ise $\$ 2,75$ olarak belirlenmiştir (Schiffer ve Walther, 2017). Tam sayılı programlama problemi CPLEX 12.10 çözücüsüyle, sezgisel yöntem ise Phyton 3.8 kullanılarak Intel Core i7 3.4Ghz işlemcisine ve 8GB RAM'e sahip makinede çalıştırılmıştır. 
European Journal of Science and Technology

Tablo 3. Veri setine ilişkin müşteri, görev, araç ve istasyon sayıları

\begin{tabular}{|c|c|c|c|c|}
\hline$\#$ & Müşteri sayısı & Görev sayısı & Araç sayısı & İstasyon sayısı \\
\hline 1 & 5 & 12 & 4 & 3 \\
\hline 2 & 5 & 15 & 4 & 3 \\
\hline 3 & 5 & 12 & 4 & 3 \\
\hline 4 & 5 & 14 & 4 & 3 \\
\hline 5 & 5 & 13 & 4 & 3 \\
\hline 6 & 5 & 13 & 4 & 3 \\
\hline 7 & 5 & 12 & 4 & 3 \\
\hline 8 & 5 & 13 & 4 & 3 \\
\hline 9 & 10 & 24 & 4 & 4 \\
\hline 10 & 10 & 22 & 4 & 4 \\
\hline 11 & 10 & 20 & 4 & 4 \\
\hline 12 & 10 & 22 & 4 & 4 \\
\hline 13 & 10 & 25 & 4 & 4 \\
\hline 14 & 10 & 22 & 4 & 4 \\
\hline 15 & 10 & 22 & 4 & 4 \\
\hline 16 & 10 & 25 & 4 & 4 \\
\hline 17 & 15 & 38 & 4 & 4 \\
\hline 18 & 15 & 41 & 4 & 4 \\
\hline 19 & 15 & 38 & 4 & 4 \\
\hline 20 & 15 & 35 & 4 & 4 \\
\hline 21 & 15 & 37 & 4 & 4 \\
\hline 22 & 15 & 36 & 4 & 4 \\
\hline 23 & 15 & 32 & 4 & 4 \\
\hline 24 & 15 & 35 & 4 & 4 \\
\hline 25 & 20 & 50 & 5 & 5 \\
\hline 26 & 20 & 49 & 5 & 5 \\
\hline 27 & 20 & 43 & 5 & 5 \\
\hline 28 & 20 & 42 & 5 & 5 \\
\hline 29 & 20 & 49 & 5 & 5 \\
\hline 30 & 20 & 39 & 5 & 5 \\
\hline 31 & 20 & 40 & 5 & 5 \\
\hline 32 & 20 & 42 & 5 & 5 \\
\hline 33 & 25 & 52 & 6 & 6 \\
\hline 34 & 25 & 48 & 6 & 6 \\
\hline 35 & 25 & 55 & 6 & 6 \\
\hline 36 & 25 & 55 & 6 & 6 \\
\hline 37 & 25 & 65 & 6 & 6 \\
\hline 38 & 25 & 46 & 6 & 6 \\
\hline 39 & 25 & 45 & 6 & 6 \\
\hline 40 & 25 & 50 & 6 & 6 \\
\hline
\end{tabular}

Tablo 4'te Model 1 için kesin ve sezgisel çözüm arasındaki sapma 6. sütunda verilmiş̧ir. Değisşken komşu arama sezgiseli ortalama 0.66 farkla daha iyi sonuçlara ulaştığı görülmektedir. Sezgisel yöntem 13.,14.,19. ve 24. örnekler haricinde iyileştirme sağlamıştır. Örneklerin boyutu arttıkça kesin yöntem 2 saatlik zaman limiti içerisinde optimum çözüme ulaşamamıştır. Kesin yöntem ortalama 3133,91 sn. de çözüme ulaşırken, sezgisel 527,03 sn çözüm döndürmüştür.

Üretilen veri setine ilişkin müşteri, görev, araç ve istasyon sayıları sırasıyla Tablo 3 'te gösterilmiştir. Tablo 5 ve 6 'da Model 1 ve 2’ye ait kesin ve sezgisel çözüm karşılaştırma sonuçlarını içermektedir. 
Avrupa Bilim ve Teknoloji Dergisi

Tablo 4. Model 1'e iliş̧kin karşılaş̧tırma sonuçları

\begin{tabular}{|c|c|c|c|c|c|c|c|}
\hline \multirow{2}{*}{$\begin{array}{l}\text { Örnek } \\
\#\end{array}$} & \multicolumn{2}{|c|}{$\begin{array}{c}\text { Tam sayılı } \\
\text { programlama }\end{array}$} & \multicolumn{5}{|c|}{ Değişken komşu arama } \\
\hline & $\begin{array}{c}\text { Amaç } \\
\text { fonksiyonu }\end{array}$ & $\begin{array}{l}\text { Çalışma } \\
\text { zamanı }\end{array}$ & $\begin{array}{c}\text { Amaç } \\
\text { fonksiyonu }\end{array}$ & $\begin{array}{l}\text { Çalışma } \\
\text { zamanı }\end{array}$ & Sapma \% & $\begin{array}{c}\text { Kullanılan toplam } \\
\text { araç sayısı }\end{array}$ & $\begin{array}{c}\text { Kaç farklı araç } \\
\text { kullanıldığı }\end{array}$ \\
\hline 1 & 339,75 & 3,05 & 339,75 & 378,69 & 0,00 & 5 & 3 \\
\hline 2 & 352,67 & 3,62 & 352,67 & 413,53 & 0,00 & 5 & 3 \\
\hline 3 & 356,80 & 5,54 & 356,80 & 398,23 & 0,00 & 5 & 2 \\
\hline 4 & 330,91 & 2,45 & 330,91 & 341,87 & 0,00 & 5 & 4 \\
\hline 5 & 340,79 & 3,02 & 340,79 & 327,81 & 0,00 & 5 & 4 \\
\hline 6 & 341,90 & 2,80 & 341,90 & 400,24 & 0,00 & 5 & 3 \\
\hline 7 & 345,78 & 2,35 & 345,78 & 392,38 & 0,00 & 5 & 3 \\
\hline 8 & 356,91 & 4,09 & 356,91 & 339,86 & 0,00 & 5 & 4 \\
\hline 9 & 364,17 & 12,81 & 364,17 & 526,75 & 0,00 & 5 & 3 \\
\hline 10 & 331,21 & 11,40 & 331,21 & 485,53 & 0,00 & 5 & 3 \\
\hline 11 & 331,20 & 10,42 & 331,20 & 522,63 & 0,00 & 5 & 1 \\
\hline 12 & 332,40 & 11,32 & 332,39 & 476,61 & 0,00 & 5 & 3 \\
\hline 13 & 332,25 & 13,52 & 334,61 & 518,76 & 0,71 & 5 & 2 \\
\hline 14 & 320,83 & 11,44 & 330,87 & 453,62 & 3,13 & 5 & 2 \\
\hline 15 & 345,45 & 12,11 & 345,45 & 498,04 & 0,00 & 5 & 3 \\
\hline 16 & 335,19 & 12,45 & 335,19 & 405,65 & 0,00 & 5 & 4 \\
\hline 17 & 364,50 & 7200,00 & 355,59 & 603,61 & $-2,44$ & 5 & 3 \\
\hline 18 & 393,38 & 5761,56 & 393,38 & 531,32 & 0,00 & 5 & 2 \\
\hline 19 & 345,75 & 47,90 & 347,05 & 570,57 & 0,38 & 5 & 3 \\
\hline 20 & 391,77 & 3603,21 & 391,77 & 541,01 & 0,00 & 5 & 4 \\
\hline 21 & 395,81 & 116,16 & 395,80 & 586,51 & 0,00 & 5 & 4 \\
\hline 22 & 372,37 & 134,56 & 372,37 & 560,87 & 0,00 & 5 & 3 \\
\hline 23 & 381,18 & 7200,00 & 373,57 & 517,90 & $-2,00$ & 5 & 3 \\
\hline 24 & 346,33 & 120,32 & 346,62 & 519,32 & 0,08 & 5 & 3 \\
\hline 25 & 413,23 & 7200,00 & 407,59 & 584,95 & $-1,36$ & 5 & 4 \\
\hline 26 & 306,58 & 7200,00 & 298,70 & 593,04 & $-2,57$ & 4 & 3 \\
\hline 27 & 341,71 & 7200,00 & 336,23 & 594,99 & $-1,60$ & 5 & 2 \\
\hline 28 & 360,53 & 184,24 & 360,53 & 518,10 & 0,00 & 5 & 4 \\
\hline 29 & 392,09 & 68,30 & 392,09 & 625,42 & 0,00 & 5 & 4 \\
\hline 30 & 386,33 & 7200,00 & 379,84 & 595,72 & $-1,68$ & 5 & 3 \\
\hline 31 & 391,53 & 7200,00 & 384,96 & 608,72 & $-1,68$ & 5 & 2 \\
\hline 32 & 364,48 & 7200,00 & 358,80 & 675,93 & $-1,56$ & 5 & 3 \\
\hline 33 & 375,69 & 7200,00 & 369,49 & 694,35 & $-1,65$ & 5 & 4 \\
\hline 34 & 373,82 & 7200,00 & 366,97 & 571,69 & $-1,83$ & 5 & 3 \\
\hline 35 & 335,11 & 7200,00 & 327,19 & 604,83 & $-2,36$ & 4 & 2 \\
\hline 36 & 202,63 & 7200,00 & 199,44 & 638,59 & $-1,57$ & 3 & 1 \\
\hline 37 & 330,84 & 7200,00 & 324,06 & 783,34 & $-2,05$ & 5 & 3 \\
\hline 38 & 361,36 & 7200,00 & 353,15 & 561,13 & $-2,27$ & 5 & 3 \\
\hline 39 & 359,86 & 7200,00 & 351,59 & 552,04 & $-2,30$ & 5 & 4 \\
\hline 40 & 365,80 & 7200,00 & 359,09 & 567,12 & $-1,84$ & 5 & 3 \\
\hline Min & & 2,35 & & 327,81 & $-2,57$ & 3,00 & 1,00 \\
\hline Mak & & 7200,00 & & 783,34 & 3,13 & 5,00 & 4,00 \\
\hline Ort & & 3133,91 & & 527,03 & $-0,66$ & 4,90 & 3,00 \\
\hline
\end{tabular}

Tablo 5'te ise Model 2'ye ait sonuçlar verilmiştir. Değişken komşu arama sezgiseli ortalama 0.10 farkla daha iyi sonuçlara ulaştığ1 görülmektedir. Sezgisel yöntem benzer şekilde 13.,14.,19. ve 24. örnekler haricinde iyileştirme sağlamıştır. Örneklerin boyutu arttıkça kesin yöntem 2 saatlik zaman limiti içerisinde optimum ç̧̈züme ulaşamamıştır. Kesin yöntem ortalama 3097,47 sn. de çözüme ulaşırken, sezgisel 550,16 sn çözüm döndürmüş̧ür. 
European Journal of Science and Technology

Tablo 5. Model 2'ye ilişkin karşılaştırma sonuçları

\begin{tabular}{|c|c|c|c|c|c|c|c|}
\hline \multirow{2}{*}{$\begin{array}{l}\text { Örnek } \\
\#\end{array}$} & \multicolumn{2}{|c|}{$\begin{array}{c}\text { Tam sayilı } \\
\text { programlama }\end{array}$} & \multicolumn{5}{|c|}{ Değişken komşu arama } \\
\hline & $\begin{array}{c}\text { Amaç } \\
\text { fonksiyonu }\end{array}$ & $\begin{array}{l}\text { Çalışma } \\
\text { zamanı }\end{array}$ & $\begin{array}{c}\text { Amaç } \\
\text { fonksiyonu }\end{array}$ & $\begin{array}{l}\text { Çalışma } \\
\text { zamanı }\end{array}$ & Sapma \% & $\begin{array}{c}\text { Kullanılan } \\
\text { toplam araç } \\
\text { sayısı }\end{array}$ & $\begin{array}{c}\text { Kaç farklı araç } \\
\text { kullanıldığı }\end{array}$ \\
\hline 1 & 353,42 & 3,47 & 353,41 & 390,96 & 0,00 & 5 & 4 \\
\hline 2 & 361,63 & 6,44 & 361,63 & 426,97 & 0,00 & 5 & 4 \\
\hline 3 & 370,95 & 3,82 & 370,95 & 414,16 & 0,00 & 5 & 3 \\
\hline 4 & 341,92 & 2,41 & 341,92 & 360,63 & 0,00 & 5 & 3 \\
\hline 5 & 354,54 & 5,36 & 354,54 & 342,85 & 0,00 & 5 & 3 \\
\hline 6 & 357,07 & 2,55 & 357,07 & 416,28 & 0,00 & 5 & 2 \\
\hline 7 & 359,53 & 2,40 & 359,53 & 408,54 & 0,00 & 5 & 2 \\
\hline 8 & 373,41 & 5,05 & 373,41 & 352,15 & 0,00 & 5 & 3 \\
\hline 9 & 386,96 & 11,31 & 386,96 & 547,01 & 0,00 & 5 & 2 \\
\hline 10 & 358,54 & 10,46 & 358,54 & 512,41 & 0,00 & 5 & 2 \\
\hline 11 & 349,67 & 12,83 & 349,67 & 545,61 & 0,00 & 5 & 2 \\
\hline 12 & 356,25 & 10,90 & 356,24 & 497,17 & 0,00 & 5 & 4 \\
\hline 13 & 353,77 & 13,01 & 356,82 & 539,66 & 0,86 & 5 & 2 \\
\hline 14 & 338,07 & 12,79 & 345,31 & 479,24 & 2,14 & 5 & 4 \\
\hline 15 & 369,12 & 12,29 & 369,12 & 516,64 & 0,00 & 5 & 2 \\
\hline 16 & 357,86 & 14,27 & 357,86 & 428,39 & 0,00 & 5 & 3 \\
\hline 17 & 391,39 & 7200,00 & 390,10 & 633,25 & $-0,33$ & 5 & 2 \\
\hline 18 & 418,90 & 7200,00 & 418,00 & 550,05 & $-0,22$ & 5 & 2 \\
\hline 19 & 371,61 & 873,50 & 375,90 & 591,67 & 1,15 & 5 & 4 \\
\hline 20 & 415,00 & 38,62 & 415,00 & 566,65 & 0,00 & 5 & 2 \\
\hline 21 & 426,46 & 86,26 & 426,46 & 605,97 & 0,00 & 5 & 3 \\
\hline 22 & 394,57 & 69,28 & 394,57 & 589,44 & 0,00 & 5 & 2 \\
\hline 23 & 408,68 & 7200,00 & 404,43 & 544,89 & $-1,04$ & 5 & 3 \\
\hline 24 & 373,62 & 26,01 & 375,27 & 546,70 & 0,44 & 5 & 3 \\
\hline 25 & 449,58 & 7200,00 & 448,96 & 611,92 & $-0,14$ & 5 & 3 \\
\hline 26 & 329,27 & 7200,00 & 327,96 & 620,18 & $-0,40$ & 4 & 3 \\
\hline 27 & 361,82 & 7200,00 & 360,75 & 620,15 & $-0,29$ & 5 & 5 \\
\hline 28 & 388,43 & 208,66 & 388,43 & 548,61 & 0,00 & 5 & 3 \\
\hline 29 & 432,90 & 67,20 & 432,90 & 650,92 & 0,00 & 5 & 4 \\
\hline 30 & 418,51 & 7200,00 & 417,08 & 620,14 & $-0,34$ & 5 & 3 \\
\hline 31 & 421,93 & 7200,00 & 414,87 & 634,27 & $-1,67$ & 5 & 4 \\
\hline 32 & 391,98 & 7200,00 & 391,09 & 701,47 & $-0,23$ & 5 & 3 \\
\hline 33 & 412,35 & 7200,00 & 410,93 & 720,36 & $-0,35$ & 5 & 5 \\
\hline 34 & 403,90 & 7200,00 & 402,48 & 599,58 & $-0,35$ & 5 & 3 \\
\hline 35 & 376,52 & 7200,00 & 369,02 & 629,56 & $-1,99$ & 4 & 2 \\
\hline 36 & 220,05 & 7200,00 & 219,40 & 665,34 & $-0,29$ & 3 & 1 \\
\hline 37 & 413,63 & 7200,00 & 412,58 & 805,91 & $-0,25$ & 6 & 3 \\
\hline 38 & 382,88 & 7200,00 & 382,11 & 593,58 & $-0,20$ & 5 & 4 \\
\hline 39 & 383,32 & 7200,00 & 381,94 & 579,71 & $-0,36$ & 5 & 2 \\
\hline 40 & 391,55 & 7200,00 & 390,27 & 597,52 & $-0,33$ & 5 & 3 \\
\hline Min & & 2,40 & & 342,85 & $-1,99$ & 3,00 & 1,00 \\
\hline Mak & & 7200,00 & & 805,91 & 2,14 & 6,00 & 5,00 \\
\hline Ort & & 3097,47 & & 550,16 & $-0,10$ & 4,93 & 2,93 \\
\hline
\end{tabular}

Tablo 4 ve 5 'te her bir örnek için modellerin kullandığı araç sayıları özetlenmiştir. Yedinci sütunlarda kullanılan araçlar verilirken, sekizinci sütunlarda kaç farklı araç kullanıldığı verilmiştir. Ortalamada Model 1 4,9, Model 2 4,93 araç kullanmıştır. Kullanılan araç sayıları birbirine çok yakındır. Kaç farklı araç kullanıldı̆̆ konusunda ise Model 13 ve Model 2,93 araç kullanmıştır. Tablo 6'da ise modellerin kullandığı istasyon sayıları özetlenmiştir. 
Tablo 6. Modellere ilişkin istasyon bazında karşılaştırma sonuçları

\begin{tabular}{|c|c|c|c|c|}
\hline \multirow{2}{*}{$\begin{array}{l}\text { Örnek } \\
\#\end{array}$} & \multicolumn{2}{|c|}{$\begin{array}{r}\text { Model 1 } \\
\end{array}$} & \multicolumn{2}{|c|}{$\begin{array}{r}\text { Model } 2 \\
\end{array}$} \\
\hline & $\begin{array}{c}\text { Kullanılan toplam } \\
\text { istasyon sayısı }\end{array}$ & $\begin{array}{c}\text { Açılan istasyon } \\
\text { sayısı }\end{array}$ & $\begin{array}{c}\text { Kullanılan toplam } \\
\text { istasyon sayısı }\end{array}$ & $\begin{array}{c}\text { Açılan istasyon } \\
\text { sayısı }\end{array}$ \\
\hline 1 & 8 & 3 & 4 & 2 \\
\hline 2 & 6 & 3 & 3 & 2 \\
\hline 3 & 7 & 2 & 5 & 1 \\
\hline 4 & 5 & 1 & 4 & 1 \\
\hline 5 & 5 & 2 & 5 & 2 \\
\hline 6 & 7 & 2 & 5 & 2 \\
\hline 7 & 5 & 2 & 5 & 2 \\
\hline 8 & 6 & 2 & 6 & 2 \\
\hline 9 & 13 & 4 & 7 & 3 \\
\hline 10 & 10 & 2 & 9 & 3 \\
\hline 11 & 9 & 2 & 6 & 2 \\
\hline 12 & 12 & 3 & 8 & 2 \\
\hline 13 & 11 & 3 & 7 & 2 \\
\hline 14 & 8 & 2 & 6 & 2 \\
\hline 15 & 9 & 3 & 8 & 3 \\
\hline 16 & 9 & 2 & 8 & 2 \\
\hline 17 & 11 & 3 & 10 & 3 \\
\hline 18 & 13 & 3 & 8 & 3 \\
\hline 19 & 14 & 4 & 10 & 4 \\
\hline 20 & 12 & 3 & 8 & 2 \\
\hline 21 & 13 & 3 & 11 & 3 \\
\hline 22 & 10 & 3 & 8 & 2 \\
\hline 23 & 10 & 3 & 10 & 3 \\
\hline 24 & 14 & 3 & 11 & 3 \\
\hline 25 & 16 & 4 & 12 & 4 \\
\hline 26 & 12 & 3 & 8 & 2 \\
\hline 27 & 12 & 4 & 7 & 5 \\
\hline 28 & 16 & 4 & 8 & 3 \\
\hline 29 & 15 & 3 & 14 & 3 \\
\hline 30 & 11 & 3 & 11 & 3 \\
\hline 31 & 15 & 4 & 10 & 3 \\
\hline 32 & 11 & 3 & 10 & 3 \\
\hline 33 & 20 & 6 & 11 & 5 \\
\hline 34 & 17 & 6 & 11 & 4 \\
\hline 35 & 16 & 5 & 15 & 5 \\
\hline 36 & 7 & 2 & 6 & 2 \\
\hline 37 & 9 & 2 & 8 & 2 \\
\hline 38 & 15 & 4 & 7 & 3 \\
\hline 39 & 14 & 4 & 7 & 3 \\
\hline 40 & 19 & 5 & 9 & 4 \\
\hline Min & 5,00 & 1,00 & 3,00 & 1,00 \\
\hline Mak & 20,00 & 6,00 & 15,00 & 5,00 \\
\hline Ort & 11,30 & 3,13 & 8,15 & 2,75 \\
\hline
\end{tabular}

Model 1'in amaç fonksiyonunda istasyon kullanım maliyeti olmadığı göz önüne alınırsa, sonuçlara göre araçlar ortalamada 11,30 kere istasyon kullanmış ve ortalamada 3,13 istasyon açıldığı anlaşılmıştır. Model 2 sonuçlarına göre ortalama 8,15 kere istasyon kullanılmış ve ortalama 2,75 istasyon açılmıştır.

\section{Sonuçlar}

Bu çalışmada, Elektrikli Araçla Periyodik Teknisyen Rotalama ve Şarj İstasyonu Yeri Belirleme Problemi ele alınmıştır. Klasik personel rotalama ve çizelgeleme problemine, elektrikli araçlar ve onların kullandığı istasyonlar dâhil edilmiştir. Karma tam sayılı programlama ile problem modellenmiştir. Gerçek hayat verisinden üretilen veri seti CPLEX çözüsüsü ile de çözülmüştür. Ayrıca farklı boyutlardaki problemlerin çözümü için değişken komşu arama sezgiseli kullanılmıştır. CPLEX çözüsüsü ile elde edilen sonuçlar değiş̧ken komşu arama sezgiseli ile karşılaştırılmıştır. Gerçekleştirilen hesaplamalı karşılaştırma analizleri sezgisel yöntemin optimum çözümü bulabildiğini ve CPLEX çözücüsünden daha iyi sonuçlar ürettiğini ortaya koymaktadır.

\section{Kaynakça}

Castillo-Salazar, J. A., Landa-Silva, D., ve Qu, R. (2014). Workforce scheduling and routing problems: literature survey and computational study. Annals of Operations Research, 1-29. doi:10.1007/s10479-014-1687-2 
Cordeau, J.-F., Laporte, G., Pasin, F., ve Ropke, S. (2010). Scheduling technicians and tasks in a telecommunications company. Journal of Scheduling, 13(4), 393-409. doi:10.1007/s10951-010-0188-7

Dohn, A., Kolind, E., ve Clausen, J. (2009). The manpower allocation problem with time windows and job-teaming constraints: A branch-and-price approach. Computers \& Operations Research, 36(4), 1145-1157. doi:http://dx.doi.org/10.1016/j.cor.2007.12.011

Edelstein, S. (2017). 2017 electric cars with more than 100 miles of range (updated). Retrieved from https://www.greencarreports.com/news/1107455_2017-electric-cars-with-more-than-100-miles-of-range

Ernst, A. T., Jiang, H., Krishnamoorthy, M., ve Sier, D. (2004). Staff scheduling and rostering: A review of applications, methods and models. European Journal of Operational Research, 153(1), 3-27. doi:http://dx.doi.org/10.1016/S0377-2217(03)00095-X

European-Commission. (2011). WHITE PAPER Roadmap to a Single European Transport Area - Towards a competitive and resource efficient transport system. In.

European-Commission. (2014). WHITE PAPER Roadmap to a Single European Transport Area - Towards a competitive and resource efficient transport system. Retrieved from http://eur-lex.europa.eu/legal-content/en/ALL/?uri=celex\%3A52011DC0144

European Comission (2014). Report from the comission to the European parliament and the council-Progress towards achieving the Kyoto and EU2020 objecitves. Retrieved from

European Environment Agency. (2014). Annual European union greenhouse gas inventory 1990-2012 and inventory report 2014. (Technical report No 09/2014 ). European Environment Agency

Google. (2020). The Google Maps Distance Matrix API. Retrieved from https://developers.google.com/maps/documentation/distancematrix/intro

Hansen, P., Mladenović, N., Brimberg, J., ve Pérez, J. A. M. (2010). Variable Neighborhood Search. In M. Gendreau ve J.-Y. Potvin (Eds.), Handbook of Metaheuristics (pp. 61-86). Boston, MA: Springer US.

Kovacs, A. A., Parragh, S. N., Doerner, K. F., ve Hartl, R. F. (2012). Adaptive large neighborhood search for service technician routing and scheduling problems. Journal of Scheduling, 15(5), 579-600. doi:10.1007/s10951-011-0246-9

Schiffer, M., ve Walther, G. (2017). The electric location routing problem with time windows and partial recharging. European Journal of Operational Research, 260(3), 995-1013. doi:https://doi.org/10.1016/j.ejor.2017.01.011

Schmidt, E. (2017). Battery Electric Cars Reported Range Comparison. Retrieved from https://www.fleetcarma.com/2017-batteryelectric-cars-reported-range-comparison/

Xu, J., ve Chiu, S. Y. (2001). Effective Heuristic Procedures for a Field Technician Scheduling Problem. Journal of Heuristics, 7(5), 495-509. doi:10.1023/A:1011377929184

Zamorano, E., ve Stolletz, R. (2017). Branch-and-price approaches for the Multiperiod Technician Routing and Scheduling Problem. European Journal of Operational Research, 257(1), 55-68. doi:https://doi.org/10.1016/j.ejor.2016.06.058 